\title{
The Mechanism of Propylene Oxidation to Acrolein over Bismuth Molybdate, Copper Oxide, and Rhodium Catalysts
}

\author{
M. Imacil,${ }^{*}$ R. L. Kuczkowski, ${ }^{*}$ J. T. Groves, ${ }^{*}$ and N. W. CanT $\dagger$ \\ *Department of Chemistry, University of Michigan, Ann Arbor, Michigan 48109; and $†$ School of Chemistry. \\ Macquarie University, North Ryde, New South Wales, 2113, Australia
}

Received September 9, 1982; revised March 18, 1983

\begin{abstract}
The oxidation of $(E)$-propene-1- $d_{1}$ to acrolein over bismuth molybdate, copper oxide, and rhodium catalysts was studied to determine if the reaction proceeded with $(Z)-(E)$ randomization of the deuterium stereochemistry. Over $\mathrm{Bi}_{2} \mathrm{Mo}_{2} \mathrm{O}_{9}$ and $\mathrm{Bi}_{2} \mathrm{MoO}_{6}$, $(E)$-acrolein-3- $d_{1}:(Z)$-acrolein-3$d_{1}$ : acrolein- $1-d_{1}$ was $1: 1: 1$ consistent with a $\sigma$-allyl intermediate which rapidly converts between two equivalent forms $\left({ }^{*} \mathrm{CHD}-\mathrm{CH}=\mathrm{CH}_{2} \leftrightarrows \mathrm{CHD}=\mathrm{CH}-{ }^{*} \mathrm{CH}_{2}\right)$. With copper oxide, (E)-acrolein3- $d_{1}:(Z)$-acrolein-3- $d_{1}:$ acrolein-1- $d_{1}$, was $1: 1: 1.6$. This points to a discrimination isotope effect consistent with a $\sigma$-allyl intermediate without interconversion of equivalent forms. Over a $\mathrm{Rh} / \alpha$ $\mathrm{Al}_{2} \mathrm{O}_{3}$ catalyst, $(E)$-acrolein-3-d $d_{1}:(Z)$-acrolein-3- $d_{1}:$ acrolein-1- $d_{1}$ was $1: 0.93: 0.89$. This is consistent with an allyl intermediate along with a second minor nonallylic pathway which docs not equilibrate the terminal carbon atoms. One or both of these processes occurred with some retention of the $(E)$-deuterium stereochemistry in the acrolein-3- $d_{1}$. Over an unsupported Rh catalyst, $(E)$ acrolein-3- $d_{1}:(Z)$-acrolein-3- $d_{1}:$ acrolein- $1-d_{1}$ was $1: 0.68: 0.85$. Only the allylic pathway is evident and the reaction process occurs with incomplete randomization $(76 \pm 10 \%)$ of the $(E)$-deuterium stereochemistry in the acrolein-3- $d_{1}$.
\end{abstract}

\section{INTRODUCTION}

The catalytic oxidation of propene to acrolein has been studied from many perspectives ( $l$ ). For a number of catalysts, it has been established that the reaction proceeds through a symmetric allylic intermediate which subsequently loses the second hydrogen from either of the equivalent terminal carbon atoms. This has been determined from carbon or deuterium labeling experiments which were reviewed recently (2).

The deuterium results over bismuth molybdate $(I a-d, 3)$, copper oxide (3), and rhodium (4) are noteworthy since they are related to the catalyst systems investigated in this paper. A selection of these results are listed in Table 1. Over the oxide catalysts, an isotope effect was observed in both hydrogen abstraction steps giving rise to nonequal amounts of $d_{1}$ and $d_{2}$ acroleins from a $\mathrm{CH}_{2} \mathrm{CHCD}_{2}$ allyl intermediate. However, over supported Rh, the second hydrogen abstraction did not exhibit any isotope effect and a minor, nonallylic pathway whereby the methyl group was converted to the aldehyde was also observed. The recent work with the bismuth molybdate and rhodium systems has led to the view that oxygen incorporation in the allylic intermediate occurs prior to the loss of the second hydrogen. One possibility is for the $\pi$-allyl intermediate to convert to a $\sigma$ allyl intermediate perhaps similar to an $-\mathrm{O}-\mathrm{CH}_{2}-\mathrm{CH}=\mathrm{CH}_{2}$ intermediate derived from allyl alcohol $(l c)$.

One aspect of the allylic intermediate has interested us, viz., whether a deuterated propene (PR) labeled stereospecifically $(Z)$ or $(E)$ would retain this geometry in the intermediate through the subsequent oxidation to acrolein (ACR). An isolated allyl radical has a bent $\mathrm{C}-\mathrm{C}-\mathrm{C}$ framework (like PR and ACR) stabilized by its $\pi$ interaction. In fact the barrier to rotation for $(Z)$ - and $(E)$-allyl-1- $d_{1}$ radicals has recently been determined as $15.7 \mathrm{kcal} / \mathrm{mol}$ (5). This barrier could be further raised due to interaction with the catalyst surface. For certain reac- 
tion conditions, a $\sigma$-allyl intermediate can also convert to acrolein with some stereoselectivity (see below). Consequently, it is conceivable that the overall oxidation of $(Z)$ - or $(E)$-propene-1- $d_{1}$ might occur with some retention of the deuterium stereochemistry relative to the $\mathrm{C}_{3}$ framework.

A stereolabeled process incorporating $\sigma$ and $\pi$-allyl intermediates is explored in the reaction network described in Scheme 1 starting with $(E)-\mathrm{PR}-1-d_{1}$. If complete randomization occurs (for example, $k_{\mathrm{E}} \gg k_{\mathrm{ALA}}$ or $k_{\mathrm{ALA}}^{\prime} \gg k_{\mathrm{H}}$ ) then equal amounts of the $E$ and $Z$ isomers of ACR-3- $d_{1}$ will result. If no stereorandomization occurs $\left(k_{\mathrm{E}}=k_{\mathrm{ALA}}^{\prime}=\right.$ $k_{\mathrm{ALE}}=0$ ) then the relative amounts of $E$ and $Z$ isomers will be in the ratio of $1: 0$. Partial randomization, i.e., unequal (nonzero) amounts of the $E$ and $Z$ products, could also occur. The relative amounts of the ACR-1- $d_{1}$ species can also provide useful mechanistic information, for example,
TABLE 1

Oxidation of Deuterated Propene to Acrolein

\begin{tabular}{|c|c|c|c|c|c|}
\hline \multirow[t]{2}{*}{ Catalyst } & \multirow[t]{2}{*}{ Propene $^{a}$} & \multicolumn{3}{|c|}{$\begin{array}{c}\text { Acrolein } \\
(\%)^{b}\end{array}$} & \multirow[t]{2}{*}{ Reference } \\
\hline & & $d_{0}$ & $d_{1}$ & $d_{2}$ & \\
\hline $\mathrm{Cu}_{2} \mathrm{O}$ & $\begin{array}{l}3-d_{1} \\
1-d_{1}^{c}\end{array}$ & $\begin{array}{l}35 \\
16\end{array}$ & $\begin{array}{l}65 \\
84\end{array}$ & & $\begin{array}{l}(3 a) \\
(3 b)\end{array}$ \\
\hline $\mathrm{Bi}_{2} \mathrm{Mo}_{2} \mathrm{O}_{9}$ & $\begin{array}{l}3-d_{1} \\
1-d_{1}{ }^{c} \\
1,1-d_{2} \\
3,3,3-d_{3}\end{array}$ & $\begin{array}{l}33 \\
20\end{array}$ & $\begin{array}{l}67 \\
80 \\
35 \\
34\end{array}$ & $\begin{array}{l}65 \\
66\end{array}$ & $\begin{array}{l}(3 a) \\
(3 b) \\
(1 a, d) \\
(1 a)\end{array}$ \\
\hline $\mathrm{Bi}_{2} \mathrm{Mo}_{3} \mathrm{O}_{12}$ & $\begin{array}{l}1,1-d_{2} \\
3,3,3-d_{3}\end{array}$ & & $\begin{array}{l}30 \\
34\end{array}$ & $\begin{array}{l}70 \\
66\end{array}$ & $\begin{array}{l}(I c) \\
(I b)\end{array}$ \\
\hline $\mathrm{Rh} / \mathrm{Al}_{2} \mathrm{O}_{3}$ & $\begin{array}{l}1,1-d_{2} \\
3,3,3-d_{3}\end{array}$ & & $\begin{array}{l}42 \\
52\end{array}$ & $\begin{array}{l}58 \\
48\end{array}$ & $\begin{array}{l}(4) \\
(4)\end{array}$ \\
\hline
\end{tabular}

a Any deuterium label at C-2 which has no mechanistic significance has been ignored.

${ }^{b}$ Only the $d_{0}, d_{1}$ or $d_{1}, d_{2}$ species are listed and normalized to $100 \%$.

c Mainly the $(Z)$ isomer.

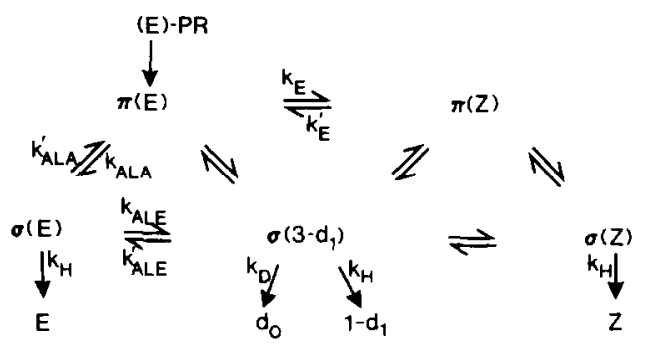<smiles>[2H]/C=C\C=C/[13CH2]</smiles><smiles>[2H]C=CCC(C)C</smiles><smiles>[2H]/C=C\C=C/C=[14CH2]</smiles><smiles>[2H]/C=C\C=C/C([2H])=[18O]</smiles><smiles>[2H]C=CC=O</smiles><smiles>[2H]/C=C\C=[18CH]</smiles><smiles>[2H][C@H](C=C)/C=C\C</smiles><smiles>[Z]=CC=CC=O</smiles> 
regarding the magnitudes of the above rate constants compared to $k_{\mathrm{H}}$ and $k_{\mathrm{D}}$ or the existence of nonallylic pathways which do not equilibrate the terminal carbon atoms.

The microwave rotational transitions of all the $d_{1}$ species of PR and ACR have been assigned $(6,7)$, so the process of randomization can be followed by their MW spectra. The analysis consists of measuring the relative intensities of suitable transitions for the various species. This provides intensity ratios which can be readily converted into molar ratios. Measurement of the amount of ACR- $d_{0}$ would also provide insight on an isotope effect but this was not followed. It was difficult to completely isolate a run with deuterated propene from the preceding stabilization process with normal propene. Moreover, information on $d_{0} / d_{1}$ ratios was initially available from the prior studies as noted above.

\section{METHODS}

All catalytic experiments were carried out in a single pass flow reactor described more completely elsewhere $(8,9)$. Reaction conditions, conversions, and selectivities for typical experiments are listed in Table 2 . The gas chromatographic analysis of the feed and effluent has been described $(9,10)$.

The two bismuth molybdate catalysts were supplied by Dr. Wilbur Swanson, Climax Molybdenum Company, Ann Arbor, Michigan. Pretreatment consisted of air oxidation at $500^{\circ} \mathrm{C}$ for $1-2 \mathrm{~h}$.

The $4 \% \mathrm{Cu}_{2} \mathrm{O} / \alpha-\mathrm{Al}_{2} \mathrm{O}_{3}$ was prepared from an aqueous solution of $\mathrm{Cu}\left(\mathrm{NO}_{3}\right)_{2}$. After impregnation, it was dried in an oven for several days and decomposed to copper oxide in an air flow at $460^{\circ} \mathrm{C}$ for $15 \mathrm{~h}$. A mixture of propene $(10 \%)$ and $\mathrm{N}_{2}$ was passed at $300^{\circ} \mathrm{C}$ in order to enhance the formation of $\mathrm{Cu}(\mathrm{I})$ oxide which is the likely catalytic species. The unsupported copper oxide $\left(\mathrm{Cu}_{2} \mathrm{O},<80\right.$ mesh, Aldrich Co.) was also pretreated in this manner.

The $1.5 \% \mathrm{Rh} / \alpha-\mathrm{Al}_{2} \mathrm{O}_{3}$ catalyst has been described previously $(4,11)$. The unsupported $\mathrm{Rh}$ metal was prepared from $\mathrm{Rh}\left(\mathrm{NO}_{3}\right)_{2} \cdot 2 \mathrm{H}_{2} \mathrm{O}(12)$. Surface areas for these catalysts were too low to be measured by conventional hydrogen chemisorption techniques. Pretreatment of each consisted of $\mathrm{H}_{2}$ reduction for several hours at $300-350^{\circ} \mathrm{C}$ for several hours following which these systems behaved similarly to the earlier study of the supported Rh catalysts $(4,11)$.

Following their pretreatment each catalyst was stabilized under reaction conditions with $\mathrm{C}_{3} \mathrm{H}_{6}$. The labeled $\mathrm{PR}$ was then introduced by diverting the oxidant flow through a U-tube containing the PR held as

TABLE 2

Typical Reaction Conditions and Characteristics of the Catalysts

\begin{tabular}{|c|c|c|c|c|c|c|}
\hline & $\mathrm{Bi}_{2} \mathrm{Mo}_{2} \mathrm{O}_{9}$ & $\mathrm{Bi}_{2} \mathrm{MoO}_{6}$ & $1.5 \% \mathrm{Rh} / \alpha-\mathrm{Al}_{2} \mathrm{O}_{3}$ & Rh powder & $\mathrm{Cu}_{2} \mathrm{O} / \alpha-\mathrm{Al}_{2} \mathrm{O}_{3}$ & $\mathrm{Cu}_{2} \mathrm{O}$ \\
\hline Surface area $\left(\mathrm{m}^{2} / \mathrm{g}\right)$ & 0.16 & 0.11 & & & 0.43 & \\
\hline Catalyst mass (g) & 3.8 & 3.8 & 2.5 & 0.1 & 1.5 & 0.5 \\
\hline Reactant feed ratio & & & & & & \\
\hline $\begin{array}{c}\mathrm{C}_{3} \mathrm{H}_{6}: \mathrm{O}_{2}: \mathrm{N}_{2} \\
\text { Total flow rate }\end{array}$ & $2: 4: 94$ & $2: 4: 94$ & $1.5: 5: 93.5$ & $1.5: 5: 93.5$ & $1: 2: 97$ & $1.5: 1.5: 97$ \\
\hline$(\mathrm{ml} / \mathrm{min})$ & 60 & 60 & 60 & 60 & 60 & 60 \\
\hline Temperature $\left({ }^{\circ} \mathrm{C}\right)$ & 450 & 450 & 180 & 200 & 250 & 230 \\
\hline $\begin{array}{l}\text { Total conversion of } \\
\mathrm{C}_{3} \mathrm{H}_{6}(\%) \\
\text { Selectivity to }\end{array}$ & 8 & 5 & 2 & 0.3 & 2 & 2 \\
\hline $\begin{array}{l}\text { acrolein }(\%) \\
\text { Selectivity to } \\
\text { acetone }(\%)\end{array}$ & 80 & 85 & 18 & 15 & 45 & 67 \\
\hline
\end{tabular}


a liquid at a suitable low temperature $(8,9)$. Approximately $1 \mathrm{mmol}$ of labeled compound was fed and the products were collected for analysis. Repassage experiments with $(Z)$-ACR-3- $d_{1}$ were conducted similarly under reaction conditions with unlabeled PR in the feed.

The method of analysis of the three $d_{1}$ acroleins by microwave spectroscopy has been described previously (9). The relative amounts of the $(Z)$ - and (E)-propene-1- $d_{1}$ were similarly determined from the intensity measurements of the same transition for each species. Three transitions were used, viz., the $1_{01}-2_{02}, 1_{11}-2_{12}$, and $1_{10}-2_{11}$ (6). In analyzing the PR- $d_{1}$ data, no corrections were made for the small methyl torsion splitting in two $(E)$-PR- $d_{1}$ transitions and the factor R needed to convert the MW intensity ratios into a molar ratio was set at 1. The uncertainties in Table 2 contain these considerations and are sufficient to encompass the experimental precision in the measurements. The latter appears to be the limiting factor for the ACR- $d_{1}$ system. The somewhat larger uncertainties for ACR- $d_{1}$ compared to the earlier study of ACR- $d_{1}(9)$ result from handling small (micromolar) levels of material particularly over the $\mathrm{Rh}$. An effort was also made to determine the equilibrium $(E)$-ACR-3- $d_{1} /$ $(Z)$-ACR-3- $d_{1}$ ratio by reanalyzing a partially equilibrated mixture which was left in a glass vessel at room temperature for 6 months. This gave 1.01(1) $(E=50.2 \pm$ $1.2 \%$ ).

The stereolabeled PR-1- $d_{1}$ was prepared by reacting methylacetylene and 9-BBN (9borabicyclo[3.3.1]nonane) in THF followed by $\mathrm{CH}_{3} \mathrm{COOD}$ (13). Unreacted methylacetylene was removed by reaction with $\mathrm{AgNO}_{3} \cdot \mathrm{NH}_{4} \mathrm{OH}$ and the propene was separated by distillation. This typically produced $75-85 \%(E)-\mathrm{PR}-d_{1}$ with the remainder as PR- $d_{0}$. The amount of ( $Z$ )-PR- $d_{1}$ was below detection limits $(<2 \%)$ so no correction for it is needed in estimating the extent of randomization.

The predominantly $(Z)$-ACR-3- $d_{1}$ used in the control experiments was obtained by the oxidative dehydrogenation of $(Z)$-allyl alcohol-3- $d_{1}$ to $(Z)$-ACR-3- $d_{1}$ as described earlier (9). The actual (E)-ACR-3- $d_{1} /(Z)$ ACR-3- $d_{1}$ used in repassage runs depended on the batch and was between 0.087 and 0.127 . Corrections were made for the $(E)$ ACR-3- $d_{1}$ so that the ratio in Table 3 for the recovered material is based on $100 \%(Z)$ ACR-3- $d_{1}$ in the feed.

\section{RESULTS AND DISCUSSION}

Analytical results for the three ACR- $d_{1}$ species as well as recovered (unreacted) PR-1- $d_{1}$ are listed in Table 3 for 15 experiments. The analysis of the extent of randomization upon passage of $(Z)$-ACR-3- $d_{1}$ in a feed containing unlabeled PR is also given for 8 of the experiments. Every effort was made to hold conditions during the repassage of $(Z)$-ACR-3- $d_{1}$ closely similar to the related experiment with $(E)$-PR-1- $d_{1}$. However, these runs frequently were separated by 4-24 h whereby exact correspondence was precluded.

In discussing these results it is helpful to distinguish between various processes and terms regarding the $\mathrm{H}$ and $\mathrm{D}$ stereochemistry. (Hereafter, the abbreviations $Z$, $E$, and $1-d_{1}$ will refer to the ACR- $d_{1}$ species unless noted.)

Symmetrization. Equivalence of end carbons as with the allyl intermediate.

Randomization. Equivalence of $\mathrm{H}$ and D as a result of $(Z)-(E)$ isomerization (i.e., cis-trans isomerization).

Product randomization. Equivalence of $\mathrm{H}$ and $\mathrm{D}$ by $(Z)-(E)$ isomerization after development of the acrolein double bond. This could occur before desorption or as a consequence of a subsequent readsorption (as experimentally verified). Rapid product randomization will produce $E=Z$ regardless of the reaction process.

Discrimination isotope effect. It is not possible to see a primary kinetic isotope effect since the slow step is abstraction from the methyl group of $(E)$-Pr-1- $d_{1}$. However, a discrimination between $\mathrm{H}$ and $\mathrm{D}$ is poten- 
TABLE 3

Relative Isotopic Distribution from Oxidation of $(E)$-Propene-1-d $d_{1}$ or Repassage of $(Z)$-Acrolein-3- $d_{1}$

\begin{tabular}{|c|c|c|c|c|c|c|c|c|c|}
\hline \multirow[t]{2}{*}{ Run } & \multirow[t]{2}{*}{ Catalyst } & \multirow{2}{*}{$\begin{array}{c}\text { Temp } \\
\left({ }^{\circ} \mathrm{C}\right)\end{array}$} & \multirow{2}{*}{$\begin{array}{c}\chi^{a} \\
(\%)\end{array}$} & \multicolumn{3}{|c|}{ Acrolein product ${ }^{b}$} & \multicolumn{2}{|c|}{ Propylene recovered ${ }^{h}$} & \multirow{2}{*}{$\begin{array}{c}\text { Acrolein } \\
\text { repassage } \\
Z /(E+Z)\end{array}$} \\
\hline & & & & $E$ & $Z$ & $1-d_{1}$ & $Z /(E+Z)$ & $\left(3-d_{1}\right) /(E+Z)$ & \\
\hline 1 & $\mathrm{Bi}_{2} \mathrm{Mo}_{2} \mathrm{O}_{9}$ & 450 & 8 & $1.00^{d}$ & $1.00^{e}$ & $1.02^{f}$ & $0.07^{d}$ & $0.07 d$ & $0.51^{d}$ \\
\hline 2 & $\mathrm{Bi}_{2} \mathrm{Mo}_{2} \mathrm{O}_{9}$ & 450 & 8 & 1.00 & 1.00 & 1.00 & 0.07 & 0.07 & \\
\hline 3 & $\mathrm{Bi}_{2} \mathrm{MoO}_{6}$ & 450 & 5 & 1.00 & 1.00 & 1.02 & 0.03 & 0.03 & \\
\hline 4 & $1.5 \% \mathrm{Rh} / \alpha-\mathrm{Al}_{2} \mathrm{O}_{3}$ & 200 & 8 & 1.00 & 0.96 & 0.92 & 0.06 & 0.02 & $0.59^{k}$ \\
\hline 5 & $1.5 \% \mathrm{Rh} / \alpha-\mathrm{Al}_{2} \mathrm{O}_{3}$ & 180 & 2 & 1.00 & 0.96 & 0.88 & 0.02 & $<0.01$ & 0.68 \\
\hline 6 & $1.5 \% \mathrm{Rh} / \alpha-\mathrm{Al}_{2} \mathrm{O}_{3}$ & 180 & 5 & 1.00 & 0.89 & $\leq 0.87$ & $<0.01$ & $<0.01$ & \\
\hline 7 & $1.5 \% \mathrm{Rh} / \alpha-\mathrm{Al}_{2} \mathrm{O}_{3}$ & 190 & 7 & 1.00 & 0.92 & 0.90 & 0.03 & 0.03 & 0.59 \\
\hline 8 & $\mathrm{Rh} /$ unsupported & 200 & 0.3 & 1.00 & 0.73 & $\leq 0.83$ & $<0.02$ & $<0.02$ & 0.84 \\
\hline 9 & Rh/unsupported & 200 & 0.5 & 1.00 & 0.62 & $\leq 0.84$ & $<0.02$ & $<0.02$ & \\
\hline 10 & Rh/unsupported & 220 & 0.9 & 1.00 & 0.73 & 0.88 & & & 0.88 \\
\hline 11 & Rh/unsupported & 200 & 0.2 & 1.00 & 0.65 & 0.84 & & & 0.85 \\
\hline 12 & $4 \% \mathrm{Cu}_{2} \mathrm{O} / \alpha-\mathrm{Al}_{2} \mathrm{O}_{3}$ & 250 & 1.3 & 1.00 & 1.04 & 1.69 & & & 0.54 \\
\hline 13 & $4 \% \mathrm{Cu}_{2} \mathrm{O} / \alpha-\mathrm{Al}_{2} \mathrm{O}_{3}$ & 250 & 1.5 & 1.00 & 0.96 & 1.63 & & & \\
\hline 14 & $4 \% \mathrm{Cu}_{2} \mathrm{O} / \alpha-\mathrm{Al}_{2} \mathrm{O}_{3}$ & 250 & 2.7 & 1.00 & 1.04 & 1.47 & $<0.01$ & $<0.01$ & \\
\hline 15 & $\mathrm{Cu}_{2} \mathrm{O} /$ unsupported & 230 & 1.9 & 1.00 & 1.04 & 1.67 & $<0.02$ & $<0.02$ & \\
\hline
\end{tabular}

a Total conversion of propylene.

${ }^{h}$ Starting material: $76 \%(E)$-propenc-1- $d_{1}, 24 \%$ propenc- $d_{0}$.

- Starting material contained predominantly PR- $d_{0}$ and $(Z)-A C R-3-d_{1}$. The ratios are corrected for the small amounts of $(E)$ ACR-3- $d_{1}$ and apply to $100 \%(Z)-A C R-3-d_{1}$.

${ }^{d}$ The $E$-ACR-3 $d_{1}$ isomer is set at 1.00 and the relative amounts of $Z$-ACR- $3 d_{1}$ and ACR-1 $d_{1}$ (with attached uncertainties) are experimentally determined.

e \pm 0.01 uncertainty for ratios in this column.

$f \pm 0.02$ uncertainty for ratios in this column.

${ }^{*}$ This ratio was 0.5 for $(Z)$-ACR-3- $d_{1}$ repassage over the $\alpha-\mathrm{Al}_{2} \mathrm{O}_{3}$ support alone.

tially measurable for the second abstraction process from the ACR- $d_{0} / \mathrm{ACR}-d_{1}$ ratio. This ratio was not followed experimentally for the reasons mentioned in the Introduction.

A discrimination between $\mathrm{H}$ and $\mathrm{D}$ may also be evident indirectly from the relative amounts of the $1-d_{1}$ and $(E+Z)$ species. If $k_{\mathrm{ALE}}$ in Scheme 1 is large, then $2 \times 1-d_{1}=$ $(E+Z)$ regardless of $k_{\mathrm{H}}$ and $k_{\mathrm{D}}$. However, if $k_{\mathrm{ALA}}^{\prime}=k_{\mathrm{ALE}}=0$, then $2 \times 1-d_{1}>(E+Z)$ when $k_{\mathrm{H}}>k_{\mathrm{D}}$. A more extensive analysis of the amounts of the $d_{0}$ and $d_{1}$ acrolein species expected from Scheme 1 for various rate constant values is explored in Table 4 . This table will be used as a basis for interpreting the reaction data.

Bismuth molybdate. The data in Table 3 for the two bismuth molybdate catalysts is clearly explainable by Schemes 1c, d, f, or $g$ (Table 4). Unfortunately, the repassage of (Z)-ACR-3- $d_{1}$ also gives essentially complete randomization so this experiment is not helpful in also demonstrating that ACR reaction randomization occurs. The equivalence of $1-d_{1}: E: Z$ in this work and the observation of a discrimination isotope effect from $d_{0}: d_{1}$ or $d_{1}: d_{2}$ ratios in previous work (Table 1) are mutually consistent with Scheme 1.

Cuprous oxide. The results over copper oxide indicate that $2 \times 1-d_{1}>(E+Z)$. This is only explicable by Scheme $1 \mathrm{~b}$ (i.e., reaction with stereoretention, followed by product randomization) or Scheme le. The relative amounts of $1-d_{1}: E: Z$ can be brought into close agreement with the data in Table 3 for $k_{\mathrm{D}} / k_{\mathrm{H}} \approx 0.25$. This value agrees well with model expectations for this temperature (14). Since control experiments with stereolabeled ACR-3- $d_{1}$ undergo nearly complete stereorandomization upon repassage, it is not possible to determine whether the randomization occurs during or after the reaction. In contrast to the bismuth molybdate results, once the $\sigma$-allyl species is formed, it does not readily interconvert to another $\sigma$-allyl isomer or revert 
TABLE 4

Relative Amounts of ACR- $d_{0}$, ACR-1- $d_{1},(E)$-ACR-3- $d_{1}$, and (Z)-ACR-3- $d_{1}$ for the Reaction Network in Scheme 1

\begin{tabular}{cccccccc}
\hline Scheme 1 & $k_{\mathrm{E}}$ & $k_{\mathrm{ALA}}^{\prime}$ & $k_{\mathrm{ALE}}$ & & \multicolumn{3}{c}{ Product acroleins $^{a}$} \\
\cline { 5 - 8 } & & & & $d_{0}$ & $1-d_{1}$ & $E$ & $Z$ \\
\hline $\mathrm{a}$ & 0 & 0 & 0 & 0.29 & 0.71 & 1 & 0 \\
$\mathrm{~b}^{b}$ & 0 & 0 & 0 & 0.29 & 0.71 & 0.50 & 0.50 \\
$\mathrm{c}$ & 0 & 0 & $\geqslant k_{\mathrm{H}}$ & 0.40 & 1 & 1 & 1 \\
$\mathrm{~d}$ & 0 & $\geqslant k_{\mathrm{H}}$ & 0 & 0.40 & 1 & 1 & 1 \\
$\mathrm{e}$ & $\Rightarrow k_{\mathrm{ALA}}$ & 0 & 0 & 0.58 & 1.42 & 1 & 1 \\
$\mathrm{f}$ & $\geqslant k_{\mathrm{ALA}}$ & 0 & $\geqslant k_{\mathrm{H}}$ & 0.40 & 1 & 1 & 1 \\
$\mathrm{~g}$ & $\gg k_{\mathrm{ALA}}$ & $\geqslant k_{\mathrm{H}}$ & 0 & 0.40 & 1 & 1 & 1 \\
$\mathrm{~h}^{c}$ & $1.50 k_{\mathrm{ALA}}$ & 0 & 0 & 0.80 & 0.80 & 1 & 0.60 \\
\hline
\end{tabular}

a Assuming $k_{\mathrm{D}} / k_{\mathrm{H}}=0.4$ except for Scheme $1 \mathrm{~h}$.

${ }^{b}$ Identical to Scheme 1a except that $E$ undergoes complete product randomization after formation.

c Product distribution from a steady-state approximation and $k_{\mathrm{D}}=k_{\mathrm{H}}$.

back to the $\pi$-allyl species. (It might also be noted that a $\sigma$-allyl species is probably not a unique structure for this "terminal" intermediate.)

The results of previous $\mathrm{Cu}_{2} \mathrm{O}$ studies (at $350^{\circ} \mathrm{C}$ ) in Table 1 can be compared with the above model. Extrapolation of $k_{\mathrm{D}} / k_{\mathrm{H}}=0.25$ to the higher reaction temperature (14) predicts a ratio of $14 / 86$ for $d_{0} / d_{1}$ from PR-1- $d_{1}$ in good agreement with the observed ratio of $16 / 84$. The same procedure applied to both hydrogen abstraction steps predicts $d_{0} / d_{1}=29 / 71$ from PR-3 $-d_{1}$. Still closer (exact) agreement with the observed value of $35 / 65$ can be obtained by increasing $k_{\mathrm{D}} / k_{\mathrm{H}}$ for the first abstraction to about $0.35-0.40$. In summary, the copper oxide results in Tables 1 and 3 appear mutually consistent with Scheme 1b or e.
Rhodium. The results for $\mathrm{Rh} / \alpha-\mathrm{Al}_{2} \mathrm{O}_{3}$ where $2 \times 1-d_{1}<(E+Z)$ do not fit any schemes in Table 4. The low value of the 1$d_{1}$ isomer is suggestive of a minor pathway where symmetrization of the end carbon atoms does not occur. This was also indicated by other isotopic studies (Table 1) and Scheme 2 was employed to analyze the results (4).

In this scheme, Path A is a symmetrization process such as the allylic mechanism in Scheme 1. Path B is a nonsymmetric or nonallylic mechanism with hydrogen loss and oxygen addition entirely at the methyl carbon such as via a hydroperoxide intermediate. Cant and Hall (4) estimated that $0.74<y<0.92$ while $f=0.49 \pm 0.04$. The latter implies that no isotope effect occurs when the allyl species further oxidizes. The

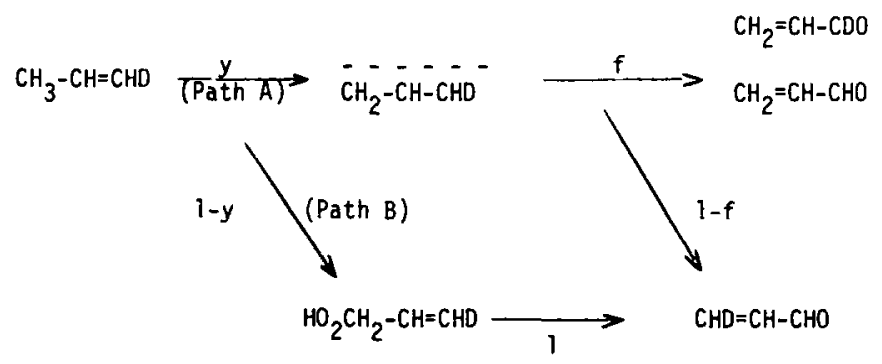

SCHEME 2 
$\mathrm{Rh} / \alpha-\mathrm{Al}_{2} \mathrm{O}_{3}$ data here are also compatible with such a scheme with the added inference that randomization during reaction is incomplete. It does not appear possible to distinguish if the allylic pathway (A) or the nonsymmetric pathway (B) alone is the origin of the nonrandomization. It is also apparent that considerable product randomization occurred by a readsorption process for this system. The $\alpha-\mathrm{Al}_{2} \mathrm{O}_{3}$ support is a factor here since repassage of stereolabeled (Z)-ACR-3- $d_{1}$ over the support alone led to complete randomization.

These results prompted experiments over unsupported $\mathrm{Rh}$ powder in an effort to: (1) significantly alter the relative contributions from paths $A$ and $B,(2)$ alter the relative amounts of the $1-d_{1}, E$, and $Z$ products, (3) minimize the subsequent readsorption-randomization process. The results in Table 3 (runs 8-11) show that these aims were achieved. They indicate that Path B is reduced to a low level since $2 \times 1-d_{1}=E+$ $Z$, within experimental uncertainty. Randomization also decreases including product randomization as demonstrated in separate repassage experiments. In fact a kinetic analysis (cf. Appendix 1) which assumes that Path B is negligible and corrects for the product randomization upon readsorption indicates that $76 \pm 10 \%$ stereorandomization from the starting material takes placc. This implics that $E=24 \%$ is obtained by a nonrandomization path while $E$ $=Z=38 \%$ is also produced from a reaction randomization pathway.

The data over unsupported rhodium which indicate that $2 \times 1-d_{1}=(E+Z)$ along with the data in Table 1 which were used to infer (4) that no isotope effect is observed when the symmetric $\mathrm{CD}_{2}-\mathrm{CH}-$
$\mathrm{CH}_{2}$ species further oxidizes to acrolein present one curious possibility to rationalize the data, viz., Scheme 1 . This pathway can approximate the relative amounts of 1$d_{1}, E$, and $Z$ but only if $k_{\mathrm{H}}=k_{\mathrm{D}}$. It seems surprising that no discrimination isotope effect would occur at the CHD terminus if the $\sigma$-allyl intermediate developed the symmetric form illustrated in 1 (Fig. 1). An alternative which preserves the $\sigma$-allyl concept would necessitate less symmetric forms such as 2-5. Formation of such intermediates could conceivably occur randomly with little or no apparent isotope effect if catalyst geometry was a factor in formation. If they did not interconvert, they could also proceed to acrolein with no evident discrimination isotope effect. Certainly, it would be worthwhile to further verify the absence of the isotope effect by determining the $d_{0} / d_{1}$ ratio from PR-1- $d_{1}$ in future experiments with this system.

Species 2-5 are probably not unique as an explanation for the data. Intermediates containing oxygen might also be possibilities (for example, $\cdot \mathrm{OCHD}-\mathrm{CH}=\mathrm{CH}_{2}$ ). In fact, any selection or abstraction of the $\mathrm{H}$ versus $\mathrm{D}$ on the CHD end of the $\pi$-allyl intermediate based primarily on geometric considerations such as proximity to the adsorption site or to the species which promotes abstraction can rationalize the ACR$d_{1}$ data over supported Rh. A more formal analysis of such a thesis is presented in Appendix 2.

Apart from the matter of the isotope effect, it is noteworthy that $(E)-P R-1-d_{1}$ can be oxidized over unsupported $R h$ via a symmetric allyl intermediate with some retention of the $(E)$ stereochemistry in the acrolein. The partial stereorandomization is
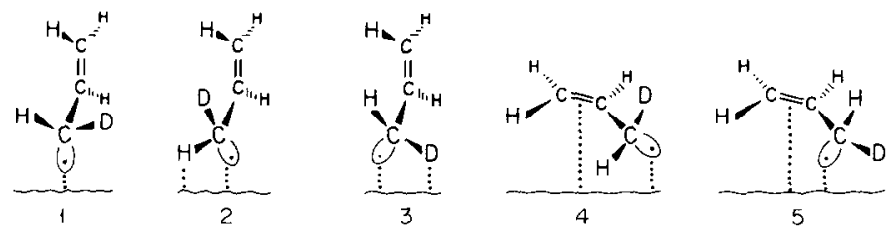

FIGURE 1 
curious although not without precedence for catalytic oxidation of alkenes over a metal catalyst $(8-10,15)$. One explanation (such as in Scheme 1) postulates a competition between the randomization kinetics of the allyl species versus subsequent reactivity to acrolein with retention. An alternative rationale could incorporate two competing reactions at different surface sites (two parallel reactions with and without randomization, respectively). Further experiments exploring the sensitivity of this randomization process to temperature, catalyst properties, and other reaction conditions may shed some light on this question but systematically exploring this for the Rh system appears quite challenging.

\section{SUMMARY}

Oxidations of $(E)$-PR-1- $d_{1}$ over bismuth molybdate, copper oxide, and unsupported Rh catalysts all indicated that a symmetrization process occurs as expected for the formation of the $\pi$-allyl intermediate. The bismuth molybdate results (both the loss of stereochemistry and $d_{1}(E+Z)$ ratio) were consistent with conversion of the $\pi$ allyl to a $\sigma$-allyl intermediate which rapidly interconverts $\quad\left({ }^{*} \mathrm{CHD}-\mathrm{CH}=\mathrm{CH}_{2} \leftrightarrows\right.$ $\left.\mathrm{CHD}=\mathrm{CH}-{ }^{*} \mathrm{CH}_{2}\right)$. The copper oxide results can be explained similarly except that the $\sigma$-allyl intermediates once formed do not interconvert. Oxidation over unsupported Rh suggest that the $\pi$-allyl intermediate might convert to a $\sigma$-allyl or another intermediate; whatever the detailed fate of the allyl intermediate may be, it further oxidizes with some retention of the original stereochemistry but without a discrimination isotope effect at that stage. Over a supported $\mathrm{Rh}$ catalyst a minor nonallylic pathway is also evident.

\section{APPENDIX 1}

The $\mathrm{Rh} / \alpha-\mathrm{Al}_{2} \mathrm{O}_{3}$ data can be analyzed via Scheme 2 to estimate the relative participation of Paths $\mathrm{A}$ and $\mathrm{B}$ and randomization limits in these paths. This utilizes the isotopic ratios in Table 3 for runs 4, 5, and 7 including the ACR-3- $d_{1}$ repassage data and employs the relationships

$$
\begin{aligned}
S=\frac{\mathrm{CH}_{2} \mathrm{CHCDO}}{\mathrm{CHDCHCHO}}= & \frac{1-d_{1}}{E+Z} \\
& =\frac{0.5 y f}{y(1-f)+(1-y)}
\end{aligned}
$$

$I=\frac{E}{Z}$ (reaction only)

$$
=\frac{y(1-f) r_{\mathrm{a}}+(1-y) r_{\mathrm{b}}}{y(1-f)\left(1-r_{\mathrm{a}}\right)+(1-y)\left(1-r_{\mathrm{b}}\right)}
$$

$F=\frac{E}{Z}($ overall $)=\frac{I r_{\mathrm{c}}+\left(1-r_{\mathrm{c}}\right)}{I\left(1-r_{\mathrm{c}}\right)+r_{\mathrm{c}}}$,

where fraction of acrolein randomization by Path $\mathrm{A}=2\left(1-r_{\mathrm{a}}\right)$, that by Path $\mathrm{B}=2(1$ $\left.-r_{\mathrm{b}}\right)$, and that by readsorption $=2\left(1-r_{\mathrm{c}}\right)$. This implies

$$
r_{\mathrm{a}}=\frac{E(\text { Path A })}{(E+Z)(\text { Path A })} \quad\left(1 \geq r_{\mathrm{a}} \geq 0.5\right)
$$

and similarly for $r_{\mathrm{b}}$ and $r_{\mathrm{c}}$. If $f$ is set at 0.5 (4) the equations contain four rate quantities $\left(y, r_{\mathrm{a}, \mathrm{b}, \mathrm{c}}\right)$ and three experimental ratios $\left(S, F, r_{\mathrm{c}}\right)$. From these values of $f$ and $S, y$ can be obtained. From $r_{\mathrm{c}}$ and $F, I$ can be obtained. With $l, y$, and $f$ fixed, the relationship between $r_{\mathrm{a}}$ and $r_{\mathrm{b}}$ can be examined but not unequivocally separated. It becomes apparent, when experimental uncertainty is considered, that the data are consistent with $r_{\mathrm{a}}=0.5-0.7$ while $r_{\mathrm{b}}$ varies between 1 and 0.5 . The data are very unrestrictive in the range of possible values for $r_{b}$ since this pathway was quite minor for these runs ( $y$ $=0.95-0.97$ ).

The same analysis for the unsupportedRh data shows it to be consistent with $y($ ave $)=1.00 \pm 0.02$ so that Path $\mathrm{B}$ has been reduced to a negligible level. The average value of $r_{\mathrm{a}}$ for runs 8,10 , and 11 is $0.62 \pm 0.05(76 \pm 10 \%$ randomization from the starting material). While this is consistent with the rough estimates of $r_{\mathrm{a}}$ over $\mathrm{Rh} /$ $\alpha-\mathrm{Al}_{2} \mathrm{O}_{3}$, that figure still does not allow much insight to be obtained on whether Path B occurs with randomization or reten- 
TABLE 5

Abstraction of Inner versus Outer Hydrogen; Relative Amounts of ACR- $d_{1}$ Products from $\pi$-Allylic- $d_{1}$ Isomers“

\begin{tabular}{|c|c|c|c|c|c|c|c|c|c|}
\hline $\mathrm{H}(\mathrm{D}) \operatorname{loss}^{b}$ & $d_{0}^{c}$ & $\begin{array}{l}H_{1}^{\prime} \\
1-d_{1}\end{array}$ & $E$ & $\bar{Z}$ & $H(D) l^{l o s s^{b}}$ & $d_{0}{ }^{c}$ & $\underset{H}{1-d_{1}}$ & $E$ & $Z$ \\
\hline i(inner) & 0 & 1 & 1 & 0 & i'(inner) & 1 & 0 & 0 & 1 \\
\hline o(outer) & 1 & 0 & 1 & 0 & $o^{\prime}$ (outer) & 0 & 1 & 0 & 1 \\
\hline
\end{tabular}

${ }^{a}$ See Appendix 2.

${ }^{b}$ Inner loss occurs from the $\mathrm{H}_{2}$ (or HD) side; outer loss occurs from the $\mathrm{H}_{3}$ (or $\mathrm{H}_{2} \mathrm{D}$ ) side.

${ }^{c} k_{\mathrm{H}}=k_{\mathrm{D}}$ apart from geometric effects.

tion over that catalyst. The value of $r_{\mathrm{a}}$ and associated data is still not sufficiently accurate or sensitive enough to Path $\mathrm{B}$ to enable a useful estimate of $r_{\mathrm{b}}$ to be made.

\section{APPENDIX 2}

A geometrically influenced discrimination between $\mathrm{H}$ and $\mathrm{D}$ from a $\pi$-allylic species will be considered. This could arise if the $(E)$-allyl-1- $d_{1}$ intermediate in Scheme 1 or Table 5 preferentially loses the next $\mathrm{H}$ (or D) from the $\mathrm{H}_{2}$ side (hereafter called the inner side) rather than the $\mathrm{H}_{2} \mathrm{D}$ site (hereafter called the outer side) or vice versa. The geometric discrimination might be associated with proximity to the adsorption site or to the species which promotes the abstraction. Apart from this geometric consideration, $k_{\mathrm{D}} / k_{\mathrm{H}}=1$. The four basic processes that can arise if stereo randomization also occurs in the $(E)$ - $\pi$-allyl species before abstraction are listed in Table 5 .

The unsupported-Rh data can be reproduced if stereo randomization of the $(E)-\pi$ allyl species to $(Z)-\pi$-allyl competes with the second abstraction. For example, $1.5(\mathrm{i}$ $+\mathrm{o})+\left(\mathrm{i}^{\prime}+\mathrm{o}^{\prime}\right)$ results in $d_{1}: E: Z=$ $2.5: 3: 2$ close to observed ratios. It is also interesting that the $d_{1}$ distribution over $\mathrm{Cu}_{2} \mathrm{O}$ in Table 3 can be approximated by $3.1(\mathrm{i}+\mathrm{o})$ followed by $E, Z$ product equilibration in a later readsorption step. How- ever, such a scheme would also predict $d_{0} /$ $d_{1} \approx 30 / 70$ starting with $(E)$-PR-1- $d_{1}$ in much poorer agreement with Voge and Adams' results (Table 1) than using Scheme $1 \mathrm{~b}$ (or 1e). The bismuth molybdate results in Table 3 can also be accommodated by combinations from Table 5 but the results in Table 1 are not reconcilable, especially the data from the $\mathrm{CD}_{2} \mathrm{CHCH}_{2}$ intermediate. Scheme 1 clearly is superior as a description of the $\mathrm{Bi}_{x} \mathrm{Mo}_{y} \mathrm{O}_{z}$ system.

\section{ACKNOWLEDGMENTS}

We are grateful to Dr. Wilbur Swanson, Climax Molybdenum Company, Ann Arbor, Michigan for providing the bismuth molybdate catalysts and several $\alpha$ alumina supports. The authors are grateful to the donors of the Petroleum Research Fund, administered by the American Chemical Society, for support of the portion of this work conducted at the University of Michigan. The National Science Foundation (Washington, D.C.) provided funds to purchase and maintain the microwave spectrometer used in this work.

\section{REFERENCES}

l. Some recent references on propylene oxidation: (a) Monnier, J. R., and Keulks, G. W., J. Catal. 68, 51 (1981); (b) Krenzke, L. D., and Keulks, G. W., J. Catal. 61, 316 (1980); (c) Burrington, J. D., Kartisek, C., and Grasselli, K. K., J. Catal. 63, 235 (1980); (d) Portefaix, J. L.. Figueras, F., and Forissier, M., J. Catal. 63, 307 (1980); (e) Inui, T., Veda, I., and Suehiro, M., J. Catal. 65, 166 (1980); ( $f$ ) Asao, I., Furakawa, S., Yamazoe, N., and Seiyama, T., J. Catal. 64, 29 (1980).

2. Keulks, G. W., Krenzke, L. D., and Notermann, T. N., in "Advances in Catalysis" (W. G. 
Frankenburg, V. I. Komarewsky, and E. K. Rideal, Eds.), Vol. 27, p. 183. Academic Press, New York, 1978.

3. (a) Adams, C. R., and Jennings, T. J., J. Catal. 2, 63 (1963); (b) ibid 3, 549 (1964).

4. Cant, N. W., and Hall, W. K., J. Catal. 22, 310 (1971).

5. Korth, H.-G., Trill, H., and Sustmann, R., J. Amer. Chem. Soc. 103, 4483 (1981).

6. Lide, Jr., D. R., and Mann, D. E., J. Chem. Phys. 35, 1374 (1961).

7. Cherniak, E. A., and Costain, C. C., J. Chem. Phys. 45, 104 (1966).

8. Egashira, M., Kuczkowski, R. L., and Cant, N. W., J. Catal. 65, 297 (1980).
9. Imachi, M., Cant, N. W., and Kuczkowski, R. L., J. Catal. 75, 404 (1982).

10. Imachi, M., Egashira, M., Kuczkowski, R. L., and Cant, N. W., J. Catal. 70, 177 (1981).

11. Cant, N. W., and Hall, W. K., J. Catal. 16, 220 (1971).

12. Sinfelt, J. H., and Yates, D. J. C., J. Catal. 8, 82 (1967).

13. Brown, H. C., Knights, E. F., and Scouten, C. G., J. Amer. Chem. Soc. 96, 7765 (1974).

14. Melander, L., in "Isotope Effects on Reaction Rates," p. 22. Ronald Press, New York, 1960.

15. Cant, N. W., and Hall, W. K., J. Catal. 52, 81 (1978). 